\title{
Validation of the Vivago Wrist-Worn accelerometer in the assessment of physical activity
}

\author{
Jérémy Vanhelst ${ }^{1,2^{*}}$, Rémy Hurdiel ${ }^{3}$, Jacques Mikulovic ${ }^{3}$, Gilles Bui-Xuân ${ }^{4}$, Paul Fardy ${ }^{5}$, Denis Theunynck ${ }^{3}$ \\ and Laurent Béghin ${ }^{1,2}$
}

\begin{abstract}
Background: Most accelerometers are worn around the waist (hip or lower back) to assess habitual physical activity. Wrist-worn accelerometers may be an alternative to the waist-worn monitors and may improve compliance in studies with prolonged wear. The aim of this study was to validate the Vivago ${ }^{\circledR}$ Wrist-Worn Accelerometer at various intensities of physical activity (PA) in adults.

Methods: Twenty-one healthy adults aged 20-34 years were recruited for the study. Accelerometer data and oxygen uptake $\left(\mathrm{VO}_{2}\right)$ were measured at sedentary, light, moderate and vigorous levels of PA.

Results: Activity categories and accelerometer counts were: sedentary, $0-15$ counts $\cdot \mathrm{min}^{-1}$; light, 16-40 counts. $\mathrm{min}^{-1}$; moderate, 41-85 counts. $\mathrm{min}^{-1}$; and vigorous activity, $>85$ counts. $\mathrm{min}^{-1}$. ANOVA repeated measures was used to determine the relationship between accelerometry data output and oxygen consumption $(r=.89 ; p<.001)$. The Bland and Altman method showed good agreement in the assessment of energy expenditure between the indirect calorimetry and the data obtained by the accelerometer.

Conclusions: Results of the study suggest that the Vivago ${ }^{\circledR}$ wrist-worn accelerometer is a valid measure of PA at varying levels of intensity. The study has also defined threshold values at 4 intensities and hence te Vivago ${ }^{\circledR}$ accelerometer may be used to quantify PA in free living conditions among adults. This device has possible application in treating a variety of important health concerns.
\end{abstract}

Keywords: Cut-off, Accelerometry, Exercise, Validation, Calibration

\section{Background}

Obesity in children and adults, coupled with adverse health consequences, has increased dramatically in recent years resulting in an urgent need for population-based interventions. The ability to prescribe exercise accurately is an important consideration in developing intervention programs [1]. Many methods are available to assess physical activity (PA) in free living conditions (FLC), e.g. PA questionnaires, self reports, indirect calorimerty, pedometry, and accelerometry [2-4]. PA questionnaires are often used because they are low cost, easily administered, and can assess large

\footnotetext{
* Correspondence: jeremy.vanhelst@chru-lille.fr

${ }^{1}$ Centre d'Investigation Clinique, CIC-PT-9301-Inserm-CH\&U, 59037, Lille, France

${ }^{2}$ Unité Inserm U995, Université Lille Nord de France, Lille, France Full list of author information is available at the end of the article
}

numbers simultaneously. However, questionnaires are subjective and have problems of reliability and validity [4-6]. Generally, the questionnaire tends to overestimate PA and can lead to misclassification of subjects [6]. Pedometers provide an inexpensive and reliable objective measure of activity by counting the number of steps performed by the subject per day. However, the pedometers are not able to quantify PA levels. Accelerometry represents an objective, inexpensive and non invasive method to measure PA [7]. The advantages of accelerometry are precision, accuracy, small size, light weight and ease of use. Accelerometry technology is based on mechanical principles incorporating a piezoelectric element and a seismic mass housed in a device called an accelerometer, which measure accelerations. Acceleration is defined as the change in velocity over time; it measures the quantity and intensity of movement. When 
the subject moves, the sensor undergoes acceleration, and the seismic mass causes the piezoelectric element to experience deformation in the form of bending, direct tension or compression. These conformational changes cause a displaced charge to build up on one side of the sensor, which can generate a variable output voltage signal that is proportional to the applied acceleration. This voltage signal, after being filtered and amplified, is then sampled at a prefixed frequency by the device to convert the analog voltage signal to a digital series of numbers, which are called "counts" [8]. Most accelerometers are usually worn around the waist, hip or lower back with an elastic belt and adjustable buckle. The Vivago ${ }^{\circledR}$ accelerometer (www.vivagowellness.fr) is a wrist-worn accelerometer, which, when compared with waist-worn monitors may be more convenient to wear and may lead to improved compliance for studies where there is prolonged wear (usually $7 \mathrm{~d}$ for assessing PA habitual). To our knowledge, no published studies have assessed the validity of the Vivago ${ }^{\circledR}$ wrist-worn accelerometer for assessing the PA in FLC.

Therefore, the purpose of the present study is to measure the validity of the Vivago ${ }^{\circledR}$ wrist-worn accelerometer in the assessment of PA and to define thresholds for detecting different levels of PA.

\section{Methods}

\section{Subjects}

Twenty-one healthy and active adults (10 females and 11 males), aged 20-34 yr, were recruited for the study. The mean \pm SD for age, body mass, and height were $29.3 \pm$ 5.1 years, $79.6 \pm 12.3 \mathrm{~kg}$, and $180.2 \pm 9.1 \mathrm{~cm}$, respectively. The purpose and objectives of the study were explained to each subject before the study began and written informed consent was obtained. The study was approved by the Lille University Research Ethics Committee (Comité de Protection des Personnes, Lille, France). All procedures were performed in accordance with the ethical standards of the Helsinki Declaration of 1975, as revised in 2008, and Good Clinical Practice [9].

\section{Procedures}

All subjects were required to undergo a physical examination to exclude pathologies that might have caused subjects to be excluded. Eligibility criteria included body mass index between 19 and $24.4 \mathrm{~kg} / \mathrm{m}^{2}, 18$ to 35 years of age, and normal clinical examination including normal psychomotor development. Exclusion criteria included obesity, chronic diseases, cardiovascular or metabolic diseases. Body mass was measured without shoes and heavy outer garments to the nearest $0.1 \mathrm{~kg}$ using an electronic scale (Oregon Scientific ${ }^{\circledR}$, GA 101, USA). Height was measured without shoes to the nearest $0.1 \mathrm{~cm}$ using a standard physician's scale. PA was assessed by accelerometry and oxygen uptake by gascollection methodology. Intensity of PA varied from sedentary to vigorous. Activities were selected that reflected typical PA in adults under normal living conditions, e.g. walking, running and sitting in the office or resting. Treadmill speed was similar to the study of Freedson et al. [10]. Subjects performed six consecutive 10 minute periods of activity at increasing levels of intensity from sedentary to vigorous. Intensities of activity were defined as sedentary (resting on a bed, and reading a book), light (walking slowly at $2.5 \mathrm{mph}$ ); moderate (walking at 3.7 $\mathrm{mph}$ and running slowly at $5 \mathrm{mph}$ ); and vigorous (running at $6.2 \mathrm{mph}$ ). A treadmill (Marquette 2000, SOMA Technology ${ }^{\circledR}$, Cheshire, USA) was used to represent light, moderate and vigorous PA. All intensities were performed during the same testing session with a rest period between each activity varying between 3 and 10 minutes according to the fatigue status of participant. The criterion chosen to restart the next activity was to recover a respiratory quotient of rest $( \pm 10 \%$ from rest period). All tests were performed at the University Applied Physiology Laboratory.

\section{Materials}

\section{Vivago ${ }^{\circledR}$ accelerometer}

Vivago ${ }^{\circledR}$ is an accelerometer worn at the wrist of the subject (Vivago Wellness ${ }^{\circledR}$, Paris, France). The activity signal, which is constructed from measured force changes at the unit's movement sensor, is continuously recorded on average once per minute and can store data recorded at 1 minute epoch. The Vivago ${ }^{\circledR}$ wrist-worn accelerometer reacts to omnidirectional changes in acceleration which generate a voltage via a piezoelectric sensor. The signal is amplified, digitized, and stored in memory as activity counts. The dynamic range of the accelerometer is $\pm 4 \mathrm{G}$. The sample rate for body motion is 40 samples per second. The Vivago ${ }^{\circledR}$ accelerometer is sensitive to movements in the $0.5-10 \mathrm{~Hz}$ range. The same accelerometer was used for all subjects. Data were downloaded from the monitor to a computer after completion of all activities. Accelerometer data between minutes 3 and 10 were used to represent physiologic steady state. Data were expressed as the mean in counts. in $^{-1}$.

\section{Indirect Calorimetry}

Oxygen consumption $\left(\mathrm{VO}_{2}\right)$ and carbon dioxide production $\left(\mathrm{VCO}_{2}\right)$ were measured every $10 \mathrm{~s}$ for $10 \mathrm{~min}$ during each activity using a gas analyzer (Respironics Novametrix Medical System ${ }^{\circledR}$ inc, NICO 7300, Wallingford, USA and Datex ${ }^{\circledR}$, Ohmeda, USA). The gas analyzer was calibrated with standard gases before each session and was synchronized with the accelerometer. Subjects wore an adapted mask that was connected by plastic tubing to the gas 
Table 1 Counts and oxygen uptake at each physical activity intensity [mean ( \pm SD)]

\begin{tabular}{|c|c|c|c|c|}
\hline & Sedentary & Light & Moderate & Vigorous \\
\hline Accelerometer (counts. $\mathrm{min}^{-1}$ ) & $6.5(5.5)$ & $18.3(2.8)$ & $45.9(8.7)$ & $95.6(5.3)$ \\
\hline Oxygen uptake (ml.kg.min $\left.{ }^{-1}\right)$ & $5.7(1.1)$ & $14.2(1.7)$ & $24.4(5.9)$ & $37.1(6.3)$ \\
\hline MET score ${ }^{\dagger}$ & $1.6(0.3)$ & $3.9(0.4)$ & $5.6(1.8)$ & $9.1(1.7)$ \\
\hline MET score* & $1.6(0.3)$ & $3.2(0.5)$ & $5.2(1.7)$ & $8.7(1.6)$ \\
\hline
\end{tabular}

${ }^{\dagger}$ MET value derived from indirect calorimetry.

* MET score derived from data accelerometer.

analyzer. The mask was worn during all experiments. Data captured between minutes 3 and 10 of each activity level were analyzed.

\section{Statistical analysis}

Data were analyzed using the Statistical Package for the Social Sciences, Windows 11.5 (SPSS Inc., Chicago, USA, IL) and Excel 2003 (Microsoft Inc., Redmond, USA, WA). Receiver operator curves (ROC) were used to determine the Vivago ${ }^{\circledR}$ value that best distinguished one level of intensity from another. The first was used to distinguish sedentary from light PA data. The threshold was defined as the maximum receiver operator curves value for sedentary PA. To define the lowest value of the subsequent PA level (i.e. light physical activity), we added one count to the preceding threshold. For example, if the threshold of the receiver operator curve for distinguishing sedentary from light PA was 15 , the range for sedentary PA was defined as $0-15$. The next threshold was 16 and corresponded to the lowest value for light PA. This procedure was repeated twice to define ranges for light, moderate, and vigorous intensities. Individual data were pooled to defined thresholds. Repeatedmeasures analysis of variance (ANOVA) was used to correlate oxygen consumption with accelerometer data for the whole study population. The Bland \& Altman method was also used to compare the energy cost assessed by the indirect calorimetry and accelerometry [11]. Heteroscedasticity was tested by the « Levene» Test for equality of variances.

\section{Results}

Vivago ${ }^{\circledR}$ accelerometer thresholds

Three ROCs were plotted according to the intensity of PA. Thresholds were identified as sedentary, light, moderate and vigorous activity. Thresholds of 15 counts. $\min ^{-1}$ between sedentary and light intensity, 40 counts. $\min ^{-1}$ between light and moderate intensity, and 85 counts. $\mathrm{min}^{-1}$ between moderate and vigorous intensity were identified. Therefore, the values ranges for sedentary, light, moderate, and vigorous activities for the Vivago ${ }^{\circledR}$ accelerometer were $0-15,16-40,41-85$, and 85 counts. $\mathrm{min}^{-1}$, respectively.

\section{Accelerometer counts, oxygen consumption and MET values}

Table 1 includes the accelerometer counts, oxygen consumption and MET values derived from calorimetry indirect and accelerometry, expressed both in minutes for each intensity. The chosen physical activities provided a wide range in MET values (1.6-8.7) with a

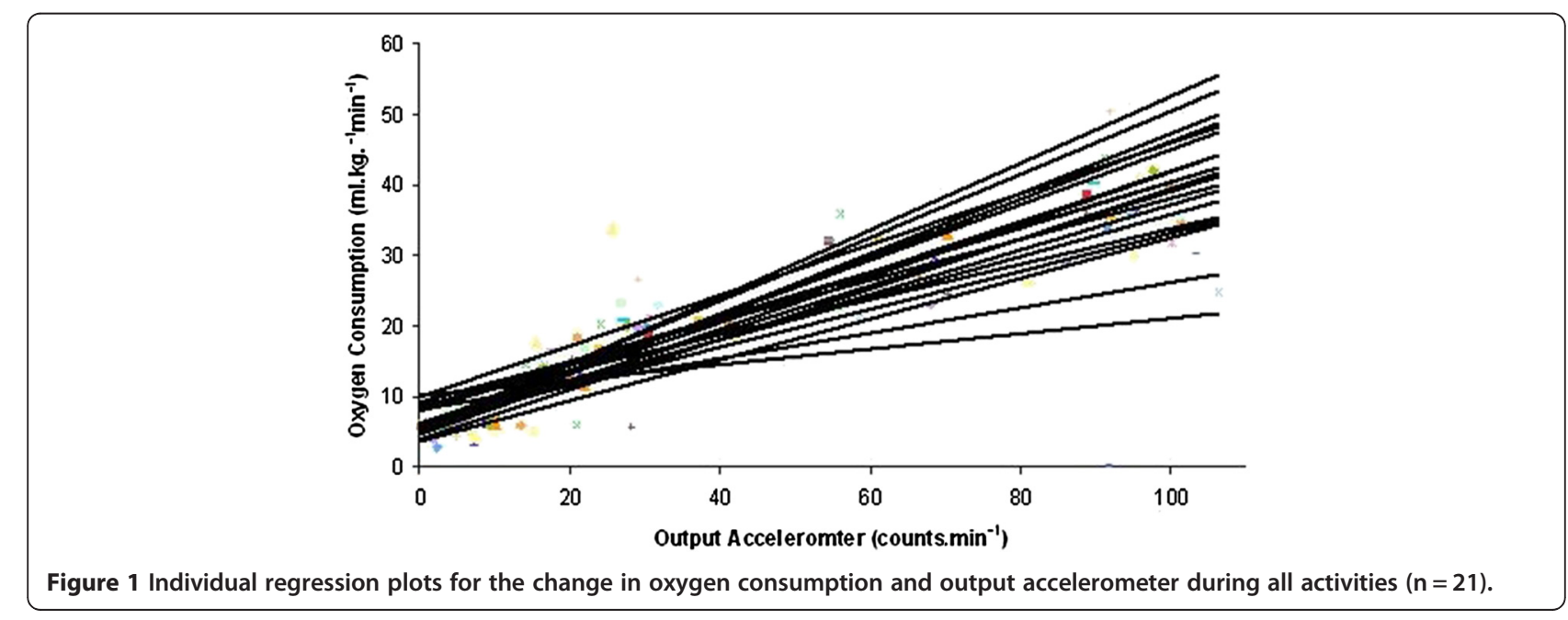




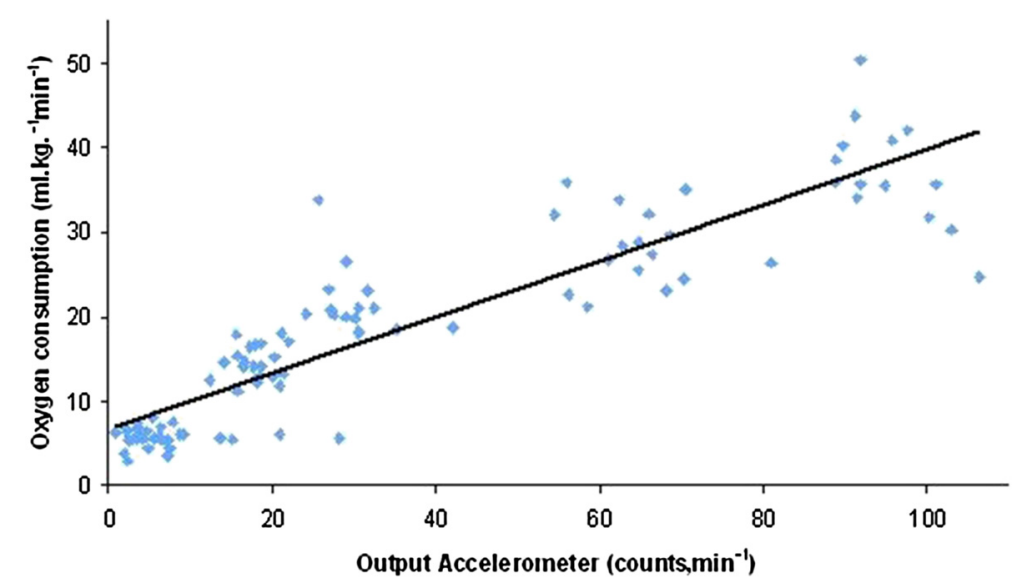

Figure 2 Correlation between output accelerometer and oxygen consumption $(n=21)$.

correspondingly wide range in accelerometer counts $\left(6.5-95.6\right.$ counts $\left.\cdot \mathrm{min}^{-1}\right)$.

Oxygen uptake, data output from the accelerometer and MET values increased with increasing exercise intensity (Table 1; Figures 1 \& 2). Within-individual, between-individual, and overall correlations for vector magnitude and oxygen consumption are presented in Table 2. Individual $r$-values between PA level, output accelerometer and oxygen uptake exceeded 0.9 in all cases.

Homoscedasticity was found for the variables because the variance was very closed. When pooling data from all participants, a significant correlation was found between output accelerometer and oxygen consumption $(\mathrm{R}=.89, \mathrm{P}<.001$; ANOVA; Figure 2). Table 1 shows that the physical activity levels were associated with a wide range of oxygen uptakes $\left(5.7-37.1 \mathrm{ml} \cdot \mathrm{kg}^{-1} \cdot \mathrm{min}^{-1}\right)$. Oxygen consumption was significantly higher at increased PA intensities.

Figure 3 shows the regression lines for MET score versus accelerometer counts. The formula estimating MET score using counts is:

$$
\mathrm{MET}=0.0949 \times\left(\text { counts. } \min ^{-1}\right)+1.9145
$$

The mixed model concordance correlation coefficient, corresponding to an $\mathrm{R}^{2}$ in standard linear regression, was 0.82 .

Figure 4 shows a good agreement in the assessment of MET values between indirect calorimetry and output

Table 2 Correlation coefficients for output accelerometer and oxygen consumption

\begin{tabular}{lccc}
\hline & Within & Between & Overall \\
\hline Correlation coefficient & 0.94 & 0.92 & 0.89 \\
\hline
\end{tabular}

accelerometer because the mean difference was within the limits of agreement and most data points were within the limits of agreement of bias (Bland \& Altman). The mean difference was very close of $0(1.1 \pm 1.3)$, and the limits of agreement were -2.9 to 2.9 .

\section{Discussion}

Accelerometry is a useful tool for prescribing exercise to help develop PA intervention programs. New accelerometers need to be tested for validity and reliability. Accelerometers most often used in epidemiological and clinical studies previously have been calibrated and validated for assessing PA patterns [12-17]. The Vivago ${ }^{\circledR}$ wrist-worn accelerometer has been validated and may be used in long-term monitoring of sleep/wake patterns with similar performance to actigraphy [18]. However, no published studies have been performed on the validity of the Vivago ${ }^{\circledR}$ wrist-worn accelerometer in the assessment of PA in FLC.

Even if many movements during activities of FLC may not be recorded with a wrist-worn accelerometer, Zhang et al. demonstrated [19] that the ability to detect certain types of PA with a wrist-worn accelerometer is comparable to waistworn accelerometers. The wrist-worn Vivago ${ }^{\circledR}$ accelerometer is a waterproof device that does not require removal during the day. As a consequence subject compliance is improved and PA patterns in FLC are assessed more precisely. When a subject wears an accelerometer around the waist with an elastic belt or on a belt clip, the subject is obliged to remove the device for sleeping, changing clothes, doing contact sports, or during activities in water, e.g. bathing, showering, and swimming. These constraints may lead a lower compliance. Furthermore, when using waist-worn accelerometers, the zero activity periods of $20 \mathrm{~min}$ or longer are analysed as "not worn time" [20,21]. If these periods are removed from the total of activity it may lead to a 


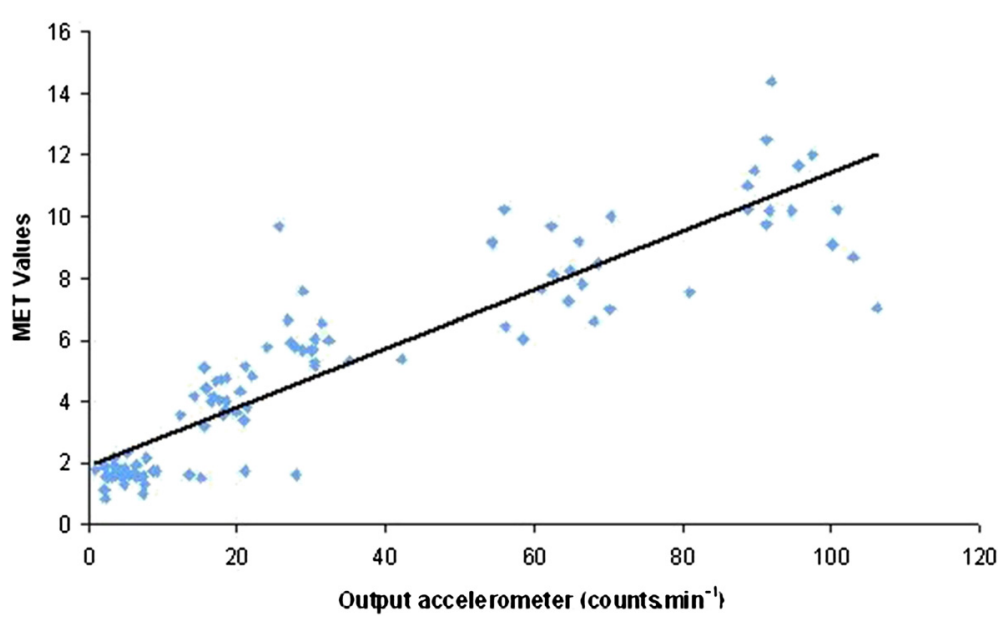

Figure 3 Regression line for MET score versus accelerometer (Vivago) counts.

misclassification of PA patterns, i.e. underestimation of sedentary time.

Controlled and noncontrolled activities were used in the study. While the majority of activities were of a controlled nature on a treadmill, two activities were not controlled, resting on a bed, and reading a book, where some participants were more active than others in spontaneous movements. The treadmill is a valid and reliable instrument for controlling different levels PA that is widely used in calibration studies [12-14]. A study showed that accelerometer output obtained on a treadmill was similar to data obtained on-land [22]. Consequently, the use of the treadmill in the present study can be extrapolated to estimate the portions of time at different levels of PA in adults under FLC.

A high correlation was found between data of the Vivago ${ }^{\circledR}$ accelerometer and oxygen consumption. In previous calibration and validation studies with others accelerometers (Acti$\operatorname{graph}^{\circledR}, \mathrm{RT} 3^{\circledR}$ accelerometer), significant correlations were observed between accelerometry and oxygen uptake. Therefore, the device was validated for assessing PA [13,17,23]. The correlation between accelerometer data and markers of
PA intensity in the present study suggest that the Vivago ${ }^{\circledR}$ accelerometer is a valid instrument for measuring PA in adults. Moreover, this result is reinforced by the Bland \& Altman method showing a good agreement in the assessment of energy expenditure (MET value) between the indirect calorimetry and the data obtained by the Vivago ${ }^{\circledR}$ wristworn accelerometer.

The Vivago ${ }^{\circledR}$ accelerometer is an original and innovative device in the assessment of PA in healthy or unhealthy populations. Its use is simple, fast and easy for data transfer. Moreover, the software interface is fun and allows for instant data interpretation. The device has possible application in treating a variety of important health concerns, as well as obesity.

This study provides useful information on the ability to the Vivago ${ }^{\circledR}$ wrist-worn accelerometer for assessing and detecting different activity levels. However, the study has some limitations. Firstly, the population was very homogeneous in age and physical fitness which may be a threat to external validity. Furthermore, the number of subjects was small and therefore less representative. To confirm our data, a second study is suggested with an

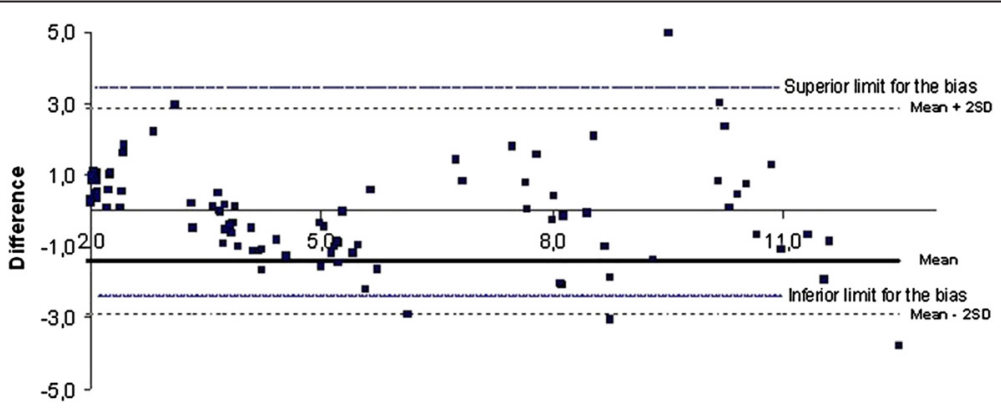

Figure 4 Difference MET values between indirect calorimetry and accelerometer output in 21 healthy volunteers. 
independent group to validate the thresholds established in laboratory and field situations. Because of the limited number of devices used in the present study, we were unable to assess intra and inter-instrument reliability. The quality of accelerometers depends on their intraand inter-instrument reliability. This is especially important for accelerometers because most studies of PA require the use of many different devices to simultaneously assess a large number of subjects. Therefore, intra and inter-instrument reliability is an important methodological issue for the choice of accelerometer device in a research study. Then, the lack of technical precisions on the Vivago accelerometer (data unavailable), specially for the equivalence in gravity force, can not permit to compare this accelerometer with the others $\left(\right.$ ActiGraph ${ }^{\circledR}, \mathrm{RT}^{\circledR}{ }^{\circledR}$, Actical $^{\circledR}$ ) used widely in the literature.

\section{Conclusions}

In conclusion, the Vivago ${ }^{\circledR}$ Wrist-Worn accelerometer is a valid technique used to assess PA in laboratory and FLC. This study provides cut-off points for adults for various levels of PA intensity using the Vivago ${ }^{\circledR}$ wristworn accelerometer measuring every minute. These thresholds enable quantification of the time spent performing sedentary, light, moderate, and vigorous activities for adults' subjects. Further research is needed to assess inter and intra instrument reliability, a key indicator of the quality of the device. Further research should also determine if the thresholds established in laboratory can be extrapolated to field or FLC where activities are more unstructured, sporadic and with many interruptions during a typical day.

\section{Competing interests}

The authors declare that they have no competing interests.

\section{Authors' contributions}

$\mathrm{JV}$ and $\mathrm{RH}$ performed the exams in this study and were involved in collecting, analyzing and interpretation the data and drafting the article. JM, GBX, and DT were involved in interpretation of the data and recruitment of subjects. PF were involved in revising article by providing significant advice and consultation. LB participated in the conception and design of the study revising and editing the manuscript. All authors read and approved the final manuscript.

\section{Acknowledgements}

The authors thank the participants for taking part in the study. There was no external funding for this research study.

\section{Author details}

'Centre d'Investigation Clinique, CIC-PT-9301-Inserm-CH\&U, 59037, Lille, France. ${ }^{2}$ Unité Inserm U995, Université Lille Nord de France, Lille, France. ${ }^{3}$ ER3S, EA4110, Université Lille Nord de France, Dunkerque, France. ${ }^{4}$ ER3S, Université d'Artois, Villeneuve d'Ascq, France. ${ }^{5}$ Department of Family, Nutrition, and Exercise Sciences (FNES) Queens College, Flushing, New York, USA.
Received: 5 March 2012 Accepted: 11 July 2012

Published: 22 August 2012

\section{References}

1. Choi B, Schnall PL, Yang H, Dobson M, Landsbergis P, Israel L, Karasek R, Baker D: Sedentary work, low physical job demand, and obesity in US workers. Am J Med 2010, 53:1088-1101.

2. Craig $C L$, Marshall AL, Sjöström M, Bauman AE, Booth ML, Ainsworth BE, Pratt M, Ekelund U, Yngve A, Sallis JF, Oja P: International physical activity questionnaire: 12-country reliability and validity. Med Sci Sports Exerc 2003, 35:1381-1395.

3. De Jonge L, DeLany JP, Nguyen T, Howard J, Hadley EC, Redman LM, Ravussin E: Validation study of energy expenditure and intake during calorie restriction using doubly labelled water and changes in body composition. Am J Clin Nutr 2007, 85:73-79.

4. Rodriguez G, Béghin L, Michaud L, Moreno LA, Turck D, Gottrand F: Comparison of the TriTrac-R3D accelerometer and a self-report activity diary with heart-rate monitoring for the assessment of energy expenditure in children. Br J Nutr 2002, 87:623-631.

5. Bond DS, Jakicic JM, Unick JL, Vithiananthan S, Pohl D, Roye GD, Ryder BA Sax HC, Wing RR: Pre- to postoperative physical activity changes in bariatric surgery patients: self report vs. objective measures. Obesity 2010, 18:2395-2397

6. Shephard RJ: Limits to the measurement of physical activity by questionnaires. Br J Sports Med 2003, 37:197-206.

7. Coleman KJ, Saelens BE, Wiedrich-Smith MD, Finn JD, Esptein LH: Relationships between TriTrac-R3D vectors, heart rate, and self-report in obese children. Med Sci Sports Exerc 1997, 29:1535-1542.

8. Chen KY, Bassett DR: The technology of accelerometry-based activity monitors: current and future. Med Sci Sports Exerc 2005, 37:S490-S500.

9. Béghin L, Castera M, Manios Y, Gilbert CC, Kersting M, De Henauw S, Kafatos A, Gottrand F, Molnar D, Sjöström M, Leclercq C, Widhalm K, Mesana MI, Moreno LA, Libersa C: Quality assurance of ethical issues and regulatory aspects relating to good clinical practices in the HELENA cross-sectional study. Int J Obes 2008, 32:S12-S18.

10. Freedson PS, Melanson E, Sirard J: Calibration of the computer science and applications, Inc. accelerometer. Med Sci Sports Exerc 1998, 30:777-781

11. Bland JM, Altman DG: Statistical methods for assessing agreement between two methods of clinical measurement. Lancet 1986, 8:307-310.

12. Vanhelst J, Béghin L, Rasoamanana P, Theunynck D, Meskini T, lliescu C, Duhamel A, Turck D, Gottrand F: RT3 accelerometer thresholds for physical activity levels in children and adolescents. J Sports Sci 2010, 28:381-387

13. Treuth MS, Schmitz K, Catellier DJ, McMurray RG, Murray DM, Almeida MJ, Going S, Norman JE, Pate R: Defining accelerometer thresholds for activity intensities in adolescent girls. Med Sci Sports Exer 2004, 36:1259-1266.

14. Puyau MR, Adolph AL, Vohra FA, Butte NF: Validation and calibration of physical activity monitors in children. Obes Res 2002, 10:150-157.

15. Evenson KR, Catellier DJ, Gill K, Ondrak KS, McMurray RG: Calibration of two objective measures of physical activity for children. J Sports Sci 2008, 26:1557-1565

16. Nichols JF, Morgan CG, Sarkin JA, Sallis JF, Calfas KJ: Validity, reliability, and calibration of the Tritrac accelerometer as a measure of physical activity. Med Sci Sports Exerc 1999, 31:908-912.

17. Freedson PS, Melanson E, Sirard J: Calibration of the computer science and application, Inc accelerometer. Med Sci Sports Exer 1998, 30:777-781.

18. Lötjönen J, Korhonen I, Hirvonen K, Eskelinen S, Myllymäki M, Partinen M: Automatic sleep-wake and nap analysis with a new wrist worn online activity monitoring device vivago WristCare. Sleep 2003, 26:86-90.

19. Zhang S, Rowlands AV, Murray P, Hurst TL: Physical activity classification using the GENEA Wrist-Worn Accelerometer. Med Sci Sports Exerc 2012, 44:742-748

20. Rey-López JP, Ruiz JR, Vicente-Rodríguez G, Gracia-Marco L, Manios Y, Sjöström M, De Bourdeaudhuij I, Moreno LA: Physical activity does not attenuate the obesity risk of TV viewing in youth. Pediatr Obes 2012, 21

21. Ruiz JR, Ortega FB, Martínez-Gómez D, Labayen I, Moreno LA, De Bourdeaudhuij I, Manios Y, Gonzalez-Gross M, Mauro B, Molnar D, Widhalm K, Marcos A, Beghin L, Castillo MJ, Sjöström M: Objectively measured physical activity and sedentary time in European adolescents: the HELENA study. Am J Epidemiol 2011, 174:173-184. 
22. Vanhelst J, Zunquin G, Theunynck D, Mikulovic J, Bui-Xuan G, Beghin L: Equivalence of accelerometer data for walking and running: treadmill versus on land. J Sports Sci 2009, 27:669-675.

23. Rowlands AV, Thomas PW, Eston RG, Topping R: Validation of the RT3 triaxial accelerometer for the assessment of physical activity. Med Sci Sports Exerc 2004, 36:518-524.

doi:10.1186/1471-2458-12-690

Cite this article as: Vanhelst et al:: Validation of the Vivago Wrist-Worn accelerometer in the assessment of physical activity. BMC Public Health 2012 12:690.

\section{Submit your next manuscript to BioMed Central} and take full advantage of:

- Convenient online submission

- Thorough peer review

- No space constraints or color figure charges

- Immediate publication on acceptance

- Inclusion in PubMed, CAS, Scopus and Google Scholar

- Research which is freely available for redistribution 